EESTI NSV TEADUSTE AKADEEMIA TOIMETISED. 21. KÖIDË

KEEMIA * GEOLOOGIA. 1972, NR. 4

ИЗВЕСТИЯ АКАДЕМИИ НАУК ЭСТОНСКОЙ ССР. ТОМ 21

ХИМИЯ * ГЕОЛОГИЯ. 1972, № 4

удК $546.131 ; 543.544$

К.ЛЭЭТС, Т. КААЛ, ИЛЬМЕ КАЛЬЯ, И. КУДРЯВЦЕВ, ЭЛЬВИ МУ'КС, МАРЕ ТАЛИ, СИГНЕ ТЕНГ, А. ЭРМ

\title{
ОПРЕДЕЛЕНИЕ СОСТАВА ПРОДУКТА КАТИОННОЙ ТЕЛОМЕРИЗАЦИИ ИЗОПРЕНА С ЕГО ИЗОМЕРНЫМИ ГИДРОХЛОРИДАМИ
}

Ранее одним из нас установлено наличие в аддукте $1: 1$ теломера изопрена с его гидрохлоридами (катализатор $\mathrm{SnCl}_{4}$ ) геранил-, линалил-, $\alpha$-терпинил-, лавандулилхлоридов, а также димера гидрохлоридов изопрена [']. Разработан метод определения в указанной смеси содержания первичных аллильных хлоридов, в том числе геранилхлорида $\left[^{2}\right]$. Позднее в нашей лаборатории идентифицирован при помощи газовой хроматографии и спєктров ЯМР в продукте гидролиза теломера еще аддукт присоединения радикала $\left(\mathrm{CH}_{3}\right)_{2} \mathrm{C}=\mathrm{CH}-\mathrm{CH}_{2}-\mathrm{K}$ изопрену в положении $4\left[{ }^{3}\right]$. Там же на основе спектра ЯМР димеру гидрохлоридов изопрена приписано строение 2-хлор-3-хлорметил-2,6-диме тилгептена-5. Независимо от нас к таким же заключениям пришли японские исследо ватели $\left[{ }^{4}\right]$. Ими установлено также, что лавандулилгалогениды омылению не подвер гаются [5]. Все выводы перечисленных выше работ основаны на исследованиях хи:иического строения оксо- или оксипроизводных, полученных различными способами из указанной смеси галогенопроизводных, потому что прямое разделение аддукта физико-химическими методами не представлялос. возможным. Однако терпеновые галогенопроизводные при реакциях омыления могуг также претерпевать аллильную перегруппировку, циклизацию или дегидрогалогенирование $\left[{ }^{6}\right]$ и поэтому вопрос о количественном и качественном составе аддукта оставался не до конца выясненным.

В настоящей работе исследовался качественный и количественный состав терпеновых хлоридов (аддуктов $1: 1$ изопрена к его изомерным гидрохлоридам - 1-хлор-3-метилбутену-2 и 3-хлор-3-метилбутену-1) с использованием нового метода газовой хроматографни галогенопроизводных [7] и встречного синтеза эталонных галогенопроизводных аддукта, разработанных нами в последние годы, так как метод препаративной газовой хроматографии (ПГХ) непряменим для выделения терпеновых галогенопроизводных ввиду нестойкости большинства этих веществ в условиях разделения. Поэтому используемые в качестве «меток» эталонные галогенопроизводные синтезировались из соответствующих спиртов установленного строения, индивидуализированных методом ПГХ и идентифицированных на основе их химических свойств и спектров ИК и ЯМР.

Геранил- и нерилхлориды синтезированы из соответствующих спиртов при помощи $\mathrm{PCl}_{5}$ с последующим выделением первичных галогенопроизводных через соединения с диметиланилином [ $\left.{ }^{8}\right]$. Линалилхлорид получен из линалоола при помощи $\mathrm{PCl}_{3}$ с последующим удалением из реакционной смеси его аллильных изомеров при помощи гексаметилентетрамина [9]. $\alpha$-Терпинилхлорид получен действием $\mathrm{PCl}_{3}$ на $\alpha$-терпинеол, выделенный методом ПІХ из теломера изопрена с уксусной кислотой после его

2 ENSV TA Toimetised $\mathrm{K} * \mathrm{G}-41972$ 
омыления [i门]. Лавандулилхлорид выделен из продукта омыления димера гидрохлоридов изопрена по методу [11]. Смесь 3-хлор-2,7-диметилоктадиена-1,6 и 1-хлор-2,7-диметилоктадиена-2,6 получена действием $\mathrm{PCl}_{5}$ на 2,7-диметилоктадиен-1,6-ол-3, выделенный из продукта омыления теломера изопрена с его гидрохлоридами при помощи ПГХ [3]. Из нее выделен первичный аллильный изомер при помощи диметиланилина $\left[{ }^{12}\right]$.

Свойства синтезированных хлорпроизводных и их газохроматографические характеристики приведены в табл. 1, хроматограммы 4-пренилгалогенопроизводных изопрена на рис. 1 и 2.

Таблица 1

Свойства синтезированных терпеновых галогенопроизводных

(в скобках присоединение $\mathrm{C}_{5} \mathrm{H}_{9} \mathrm{Cl}$ к изопрену)

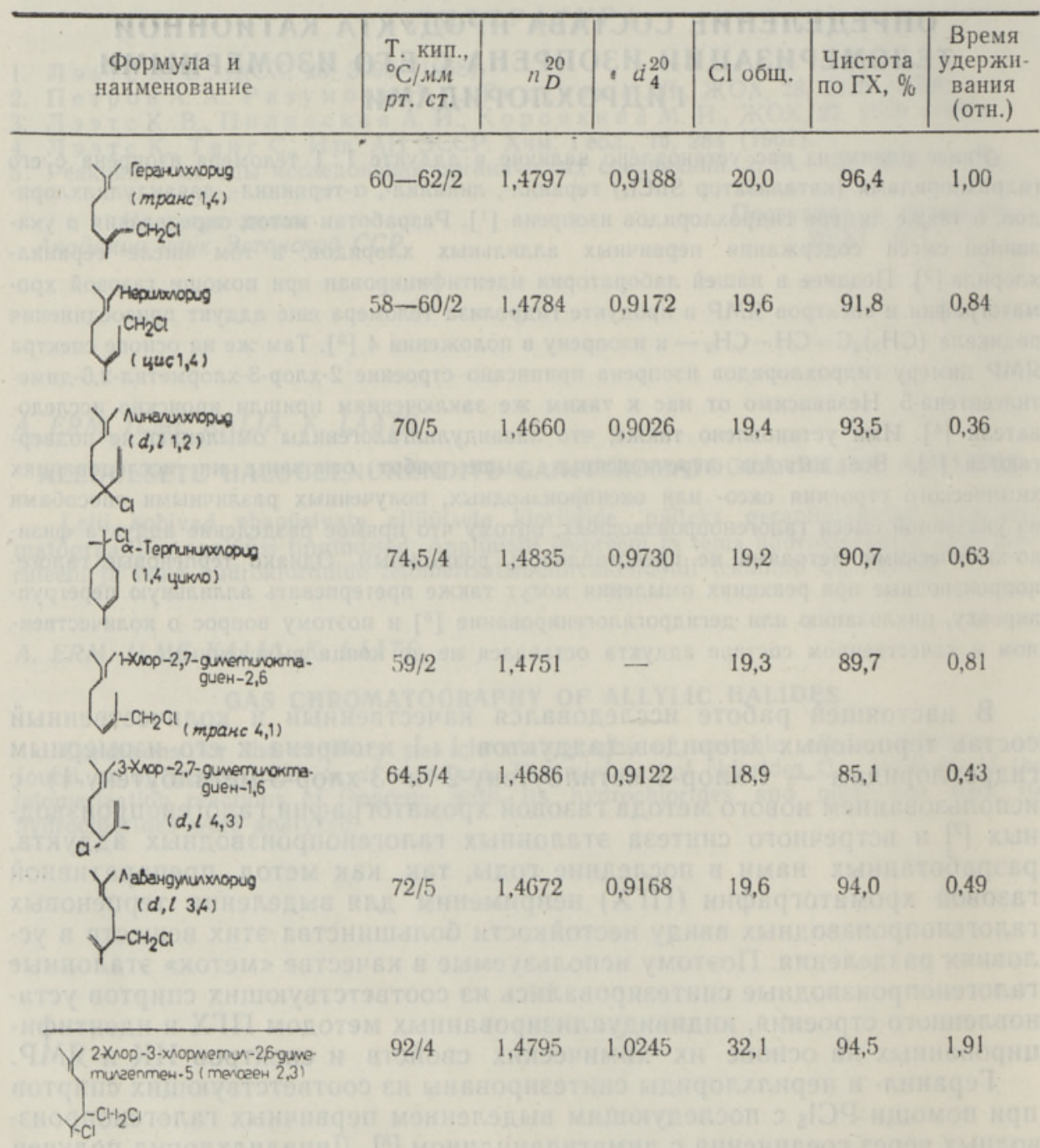

Исходные телогены - 1-хлор-3-метилбутен-2 и 3-хлор-3-метилбутен-1 выделены ректификацией из продукта гидрохлорирования изопрена с характеристикой, приведенной в табл. 2. 


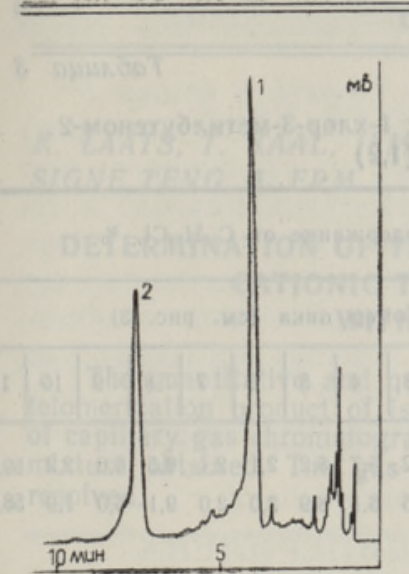

Рис. 1. Хроматограмма смеси 3-хлор-2,7-диметилоктадиена-1,6 (1) и 1хлор-2,7-диметилоктадиена-2.6 (2). Хромато граф «Хром-3» с пламенно-ионизационным детектором. Капиллярная колонка длиной 20 м, диаметром 0,37 мм, с нанесенным три- $\beta$-цианэтиловым эфиром глицерола нз $3 \%$-ного раствора, температура анализа $37^{\circ}$, температура испарителя $110^{\circ} \mathrm{C}$, скорость газа-носителя (аргон) 2,5 мл/мин.

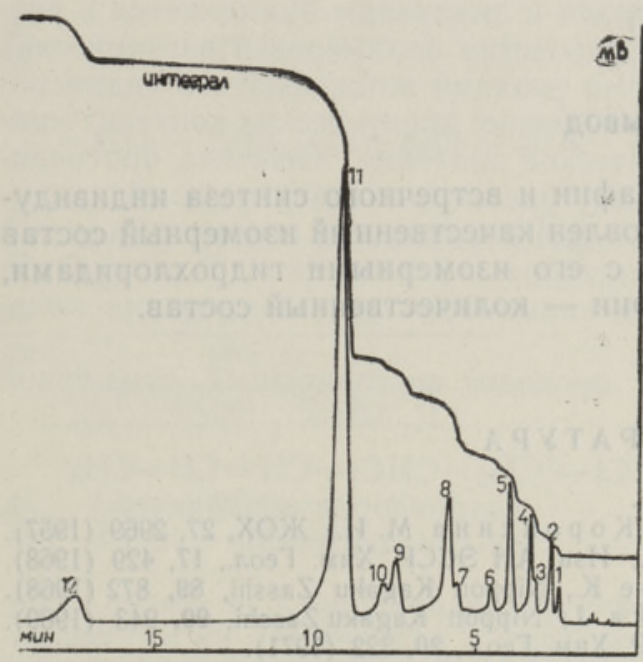

Рис. 3. Хроматограмма и интеграл хроматограммы аддукта $1: 1$ продукта реакциі теломеризации изопрена с 1-хлор-3-метилбутеном-2. $1,2,3$ и 7 неидентифицированы, 4 - линалилхлорид, 5 - 3-хлор-2,7-диметилоктадиен-1,6, 6 - лавандулилхлорид, 8 $\alpha$-терпинилхлорид, $9-1$-хлор-2,7-диметилоктадиен-2,6, 10 - нерилхлорид, 11 - геранилхлорид, 12 - димер гидрохлорида изопрена (2-хлор-3-хлорметил-2,6-диметилгептен-5). Условия анализа см. рис. 1.

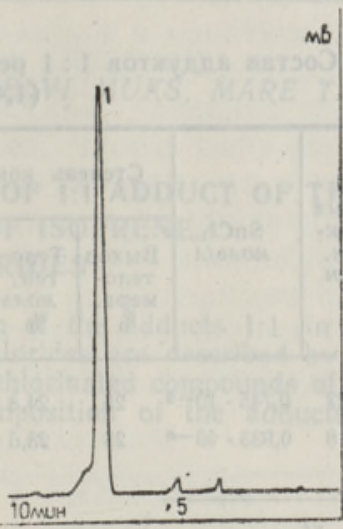

Рис. 2. Хроматограмма 1-хлор-2,7-диметилоктадиена-2,6 (1), очищенного через комплекс с диметиланилином. Условия анализа см. рис. 1 .

Условия теломеризации приведены в табл. 3, хроматограмма аддукта $1: 1$ и его идентификация - на рис. 3, рассчитанные по хроматограммам составы аддуктов - в табл. 3 .

Из полученных результатов можно заключить, что оба изомерных гидрохлорида изопрена дают почти одинаковый продукт теломеризации с присоединением к изопрену радикала 3-метилбутен-2-ила-1 в положениях 1,4 и 3 в соотношениях $100: 22: 3$. Содержание геранилхлорида в аддукте $1: 1$ составляло около $60 \%$, углеводородов $\mathrm{C}_{10}$ - не более $0,5 \%$, димера гидрохлоридов - $10 \%$. Всего в аддукте $1: 1$ идентифицировано 8 компонентов, неидентифицированными остались некоторые вещества с суммарным содержанием не более $7 \%$.

Таблица 2

Исходные телогены

\begin{tabular}{|c|c|c|c|c|}
\hline $\begin{array}{l}\text { Телоген (в скобках присое- } \\
\text { динение } \mathrm{HCl} \text { к изопрену) }\end{array}$ & $\begin{array}{c}\text { T. кинп., } \\
{ }^{\circ} \mathrm{C} / M, \mu p T . c T\end{array}$ & $n_{D}^{20}$ & $a_{4}^{20}$ & $\begin{array}{l}\text { Чистота по } \\
\text { ГХ, \% }\end{array}$ \\
\hline $\begin{array}{ll}\text { 1-Хлор-3-метилбутен-2 } & (1,4) \\
\text { 3-Хлор-3-метилбутен-1 } & (1,2)\end{array}$ & $\begin{array}{l}43-44 / 60 \\
33-34 / 140\end{array}$ & $\begin{array}{l}1,450: \\
1,4200\end{array}$ & $\begin{array}{l}0,9314 \\
0,8874\end{array}$ & $\begin{array}{l}97,6 \\
93,1\end{array}$ \\
\hline
\end{tabular}


Состав аддуктов $1: 1$ реакции теломеризации изопрена с 1-хлор-3-метилбутеном-2 $(1,4)$ и с 3 -хлор-3-метилбутеном-1 $(1,2)$

\begin{tabular}{|c|c|c|c|c|c|c|c|c|c|c|c|c|c|c|c|c|c|c|}
\hline \multirow{3}{*}{ 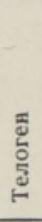 } & \multirow{3}{*}{$\begin{array}{l}\text { Время } \\
\text { реак- } \\
\text { цин, } \\
\text { мин }\end{array}$} & \multirow{3}{*}{$\underset{\text { моль/A }}{\mathrm{SnCl}_{4}}$} & \multicolumn{3}{|c|}{ Степень конверсии } & \multicolumn{2}{|c|}{$\begin{array}{c}\text { Выход от тело- } \\
\text { мера, \% }\end{array}$} & \multicolumn{11}{|c|}{ Содержание от $\mathrm{C}_{10} \mathrm{H}_{17} \mathrm{Cl}$, \% } \\
\hline & & & \multirow{2}{*}{$\begin{array}{c}\text { Выход } \\
\text { тело- } \\
\text { мера. } \\
\%\end{array}$} & \multirow{2}{*}{$\begin{array}{c}\text { Тело- } \\
\text { ген, } \\
\text { моль } \\
\%\end{array}$} & \multirow{2}{*}{$\begin{array}{c}\text { Таксо- } \\
\text { ген, } \\
\text { моль } \\
\%\end{array}$} & \multirow{2}{*}{$\begin{array}{l}\bar{U} \\
\underline{\Xi} \\
\text { İ }\end{array}$} & \multirow{2}{*}{$\frac{\underbrace{0}_{0}}{\frac{0}{0}}$} & \multicolumn{11}{|c|}{ Номер пнка (см. рнс. 3) } \\
\hline & & & & & & & & 1 & 2 & 3 & 4 & 5 & 6 & 7 & 8 & 9 & 10 & 11 \\
\hline (1, & 27 & $0,745 \cdot 10^{-}$ & 25 & 24,8 & 25,2 & 50,6 & 5 & 0,9 & 2,3 & 1,2 & 5,7 & 8,2 & 2,1 & 2,1 & 9,5 & 6,6 & 2,2 & 59,2 \\
\hline$(1.2$ & 8 & $0,933 \cdot 10-$ & 25 & 23,6 & 27,2 & 49,6 & 3,5 & 1,0 & 2,6 & 1.5 & 6.1 & 8,9 & 2,0 & 2,0 & 9,1 & 6,0 & 1,9 & 58,9 \\
\hline
\end{tabular}

Условия теломеризации: температура $23^{\circ} \mathrm{C}$, телоген : таксоген $-1: 1$ (моль), растворитель - 1,2-дихлорэтан $50 \%$ по весу, катализатор - $\mathrm{SnCl}_{4}$ (безводное).

\section{Вывод}

При помощи газовой хроматографии и встречного синтеза индивидуальных галогенопроизводных установлен качественный изомерный состав аддуктов 1:1 теломера изопрена с его изомерными гидрохлоридами, а при помощи газовой хроматографини - количественный состав.

\section{ЛИ Т Е Р А Т Р А}

1. Лээтс К. В., ЖОХ, 28, 3096 (1958).

2. Лээтс К. В., Пилявская А. И., Коровкина М. И., ЖОХ, 27, 2969 (1957),

3. Л ээтс К., Каал Т., Юр ьен С Х., Изв. АН ЭССР, Хим. Геол., 17, 429 (1968)

4. T a n a k a J., Kat agiri T., T a k a be K., Nippon Kagaku Zasshi, 89, 872 (1968).

5. T a k abe K., K at ag ir i T., T a n a ka J., Nippon Kagaku Zasshi, 90, 943 (1969).

6. Тенг С., Лээ тс К., Изв. АН ЭССР, Хим. Геол., 20, 322 (1971).

7. Эр м А., К алья И., Л ээ т с К., Изв. АН ЭССР, Хим. Геол., 21, 300 (1972).

8. Лэ э т С К., Т енг С., Изв. АН ЭССР, Хим. Геол., 16, 292 (1967).

9. Тенг С., Л ээтс К., Изв. АН ЭССР, Хим. Геол., 20, 319 (1971).

10. Эр м А., Л э э т с К., Изв. АН ЭССР, Хим. Геол., 16, 37 (1967).

11. К а ал Т., Л ээ т с К., Изв. АН ЭССР, Хим. Геол., 21, 269 (1972).

12. Л э э т с К., ЖОХ, 31, 1869 (1961).

$\begin{array}{cc}\text { Ннститут химии } & \text { Поступила в редакцию } \\ \text { Академии наук Зстонской ССР } & 16 / \text { ХII } 1971\end{array}$

K. LAATS, T. KAAL, ILME KALJA, I. KUDRJAVTSEV, ELVI MUKS, MARE TALI, SIGNE TENG, A. ERM

\section{ISOPREENI JA TEMA ISOMEERSETE HODROKLORIIDIDE KATIOONSE TELOMERISATSIOONI PRODUKTIDE KOOSTISE MÄARAMINE}

Gaasikromatograafilise analüüsi ja individuaalühendite sünteesi abil määrati kindlaks kvantitatiivsed ja kvalitatiivsed andmed isopreeni ja tema isomeersete hüdrokloriidide telomerisatsiooniproduktis leiduvate $1: 1$ adduktide kohta. Lahendati $1: 1$ adduktide gaasikromatograafilise analüüsi probleem. 
K. LAATS, T. KAAL, ILME KALJA, I. KUDRYAVTSEV, ELVI MUKS, MARE TALI. SIGNE TENG, A. ERM

\section{DETERMINATION OF THE ISOMERIC COMPOSITION OF 1:1 ADDUCT OF THE CATIONIC TELOMERIZATION PRODUCT OF ISOPRENE WITH ITS ISOMERIC HYDROCHLORIDES}

The quantitative and qualitative data of the composition of the adducts $1: 1$ in the telomerization product of isoprene with its isomeric hvdrochlnrides are describer bv aid of capillary gas chromatography and synthesis of individual chlorinated compounds of the mixture obtained. The gas chromatography of isomeric composition of the adducts is resolved. 